\title{
Mechanical Properties of Spruce Wood Extracted from GLT Beams Loaded by Fire
}

\author{
Lucie Kucíková ${ }^{1}$, Michal Šejnoha ${ }^{1}$, Tomáš Janda ${ }^{1}$, Jan Sýkora ${ }^{1}$, Pavel Padevět ${ }^{1}$ and Guido Marseglia ${ }^{2,3, *}$ \\ 1 Department of Mechanics, Faculty of Civil Engineering, Czech Technical University in Prague, \\ 16629 Prague, Czech Republic; lucie.kucikova@fsv.cvut.cz (L.K.); sejnom@fsv.cvut.cz (M.Š.); \\ tomas.janda@fsv.cvut.cz (T.J.); jan.sykora.1@fsv.cvut.cz (J.S.); pavel.padevet@fsv.cvut.cz (P.P.) \\ 2 High Technical School of Architecture, University of Seville, 41012 Seville, Spain \\ 3 Instituto de Matemáticas de la Universidad de Sevilla, University of Seville, 41012 Seville, Spain \\ * Correspondence: marseglia@us.es
}

check for updates

Citation: Kucíková, L.; Šejnoha, M.; Janda, T.; Sýkora, J.; Padevět, P.; Marseglia, G. Mechanical Properties of Spruce Wood Extracted from GLT Beams Loaded by Fire. Sustainability 2021, 13, 5494. https://doi.org/ $10.3390 /$ su13105494

Academic Editor: Domenico Mazzeo

Received: 20 March 2021

Accepted: 30 April 2021

Published: 14 May 2021

Publisher's Note: MDPI stays neutral with regard to jurisdictional claims in published maps and institutional affiliations.

Copyright: (C) 2021 by the authors Licensee MDPI, Basel, Switzerland. This article is an open access article distributed under the terms and conditions of the Creative Commons Attribution (CC BY) license (https:// creativecommons.org/licenses/by/ $4.0 /)$.

\begin{abstract}
Heating wood to high temperature changes either temporarily or permanently its physical properties. This issue is addressed in the present contribution by examining the effect of high temperature on residual mechanical properties of spruce wood, grounding on the results of full-scale fire tests performed on GLT beams. Given these tests, a computational model was developed to provide through-thickness temperature profiles allowing for the estimation of a charring depth on the one hand and on the other hand assigning a particular temperature to each specimen used subsequently in small-scale tensile tests. The measured Young's moduli and tensile strengths were accompanied by the results from three-point bending test carried out on two groups of beams exposed to fire of a variable duration and differing in the width of the cross-section, $b=100 \mathrm{~mm}$ (Group 1) and $b=160 \mathrm{~mm}$ (Group 2). As expected, increasing the fire duration and reducing the initial beam cross-section reduces the residual bending strength. A negative impact of high temperature on residual strength has also been observed from simple tensile tests, although limited to a very narrow layer adjacent to the charring front not even exceeding a typically adopted value of the zero-strength layer $d_{0}=7 \mathrm{~mm}$. On the contrary, the impact on stiffness is relatively mild supporting the thermal recovery property of wood.
\end{abstract}

Keywords: spruce wood; fire test; heat transport; Young's modulus; tensile strength

\section{Introduction}

Wood is an environmentally friendly and renewable material which promotes its use even in advanced structural applications where Glued Laminated Timber (GLT) beams, in particular, play an important role. Unlike cross-laminated timber (CLT) panels, where individual layers are stacked in alternating directions, the GLT beams are generally used as linear structural elements often in the form of large span arches with a variable crosssection. Compare to structural composite lumber (SCL) manufactured from wood veneers, strands or flakes, the GLT beams still retain the beauty of natural sawn timber, which further increases its popularity. However, regardless of a structural element used and type of application the wood combustibility combined with complex chemical and physical processes taking place at elevated temperatures calls for special attention in every design.

Although heat treatment is often desirable to increase the wood dimensional stability and biological resistance, an exposition to high temperatures may cause a considerable loss of wood strength and ductility attributed merely to a permanent degradation of wood microstructure [1,2]. Considerable research activity addressing the wood response, both immediate and residual, when subjected to high temperatures is therefore unsurprising also considering a significant variability in material properties of wood, both mechanical $[3,4]$ and physical [5]. 
Mostly, attention has been accorded to small-scale experiments. Although a testing chamber allowing for simultaneous heat treatment and loading is thought more reliable when addressing the immediate properties [6], the methods were generally limited to testing the specimens right after taking them out from a temperature chamber [2,7]. Regardless of the method used, an almost linear reduction in strength, both tensile and compressive, and stiffness has been observed in the broad range of temperatures ranging from $20^{\circ} \mathrm{C}$ to as high as $300{ }^{\circ} \mathrm{C}$. For temperatures below $200^{\circ} \mathrm{C}$, this thermal softening is typically associated with hemicellulose and lignin viscous softening with a minor contribution of hemicellulose and cellulose degradation [2,8]. For balsa wood [2], for example, it was found that most of the processes up to $250{ }^{\circ} \mathrm{C}$ are fully recoverable, partly also because the cellulose degradation is minor until $210^{\circ} \mathrm{C}$ [8]. Further details on chemical transformation of various species at elevated temperatures can be found in the review paper by Esteves and Pereira ([9], and the literature therein) also pointing out an increase of cellulose crystallinity due to degradation of amorphous cellulose because of heat treatment already below $200{ }^{\circ} \mathrm{C}$. Immediate properties of larger size $(50 \mathrm{~mm} \times 100 \mathrm{~mm} \times 2440 \mathrm{~mm})$ softwood lumber specimens in tension subjected to elevated temperature were studied in [10] putting emphasis on a rate of loading, treating temperature, and exposure time. What applies to our study is the reported negligible effect of exposure time less than one hour for temperatures below $150{ }^{\circ} \mathrm{C}$.

Contrary to small-scale experiments limiting attention to oven-temperature treatment, the full-size fire experiments accompanied by static loading to assess the time to failure for a given load and fire scenario are scarce. In this regard, the interested reader is referred to [11] reporting on the mechanical failure of GLT beams in four-point bending during the fire tests. Therein, a simple charring rate model was adopted together with the zero-strength layer of a residual cross-section to predict the time to failure. With no adjustment, such a prediction was for most fire scenarios non-conservative as no account for the reduction of immediate properties due to thermal softening on the one hand and an increase in moisture content at temperature regions below $100^{\circ} \mathrm{C}$ was considered. To arrive at a better agreement between predictions and measurements required a proper modification of the zero-strength layer. Further to this subject, the work reported in $[12,13]$ is also recommended.

Studying the response of residual structural elements exposed previously to fire is doubtless a critical task in the fire safety analysis. Additionally, it reveals thermal recovery property of wood species depending on the applied temperature. A rapid reduction of an immediate modulus of elasticity of spruce at temperatures above $200{ }^{\circ} \mathrm{C}$ was observed in [6], but it was attributed to thermal softening rather than to thermal degradation and this temperature effect was considered reversible. A similar observation for larch wood for temperature exceeding $225^{\circ} \mathrm{C}$ but in this case for both immediate and residual tensile strength and modulus of elasticity is presented in [7] indicating permanent, irrecoverable, changes to wood microstructure. A rapid reduction of strength and stiffness of balsa wood for the temperature exceeding $250{ }^{\circ} \mathrm{C}$ [2] was also associated with the permanent decomposition of the wood grain structure. On the contrary, improved residual properties for temperatures below $200{ }^{\circ} \mathrm{C}$ can be expected, see e.g., [7]. Therein, however, the exposure time was very short. Although neither [1] nor [8] confirmed this observation with reference to strength for spruce wood, the modulus of elasticity, as presented in [8], experienced a rising trend for temperatures up to $175^{\circ} \mathrm{C}$ depending on the treatment conditions. Such findings, apart from the reduction of moisture, can be supported by increasing volume fraction of crystalline cellulose at the expense of amorphous cellulose and hemicellulose degradation at high temperatures below $200^{\circ} \mathrm{C}[1,9]$. Thermal degradation of hemicellulose may, on the other hand, reduce the load shearing capacity of lignin-hemicellulose matrix [8] acting as a bonding agent in the fibrous like cell wall composite [3,4], which in turn increases its brittleness and reduces the overall strength.

The above literature survey, although by no means exhaustive, clearly highlights the complexity of the research area concerned with the behavior of thermally modified wood. 
It is our objective to contribute to this research activity. As illustrated in Figure 1, we focus on:

- Numerical prediction of through-thickness temperature profiles adopting our recently developed computational strategy proposed on the basis of large-scale fire tests. This topic is addressed in detail in Sections 2.2 and 3.2 validating the numerical predictions by experimental measurements.

- Experimental determination of residual strength and stiffness properties of wood exposed to a real fire. Our attention is limited to tensile properties aiming also at thermal recovery property of wood or a permanent impact of elevated temperature on wood microstructure at the vicinity of the charring front. This research effort also addressing the influence of natural defects such as knots is described in Sections 2.3 and 3.3 accompanied by the Pilodyn measurements of Young's modulus directly on beams and large-scale three-point bending tests on the beams sustaining fire.

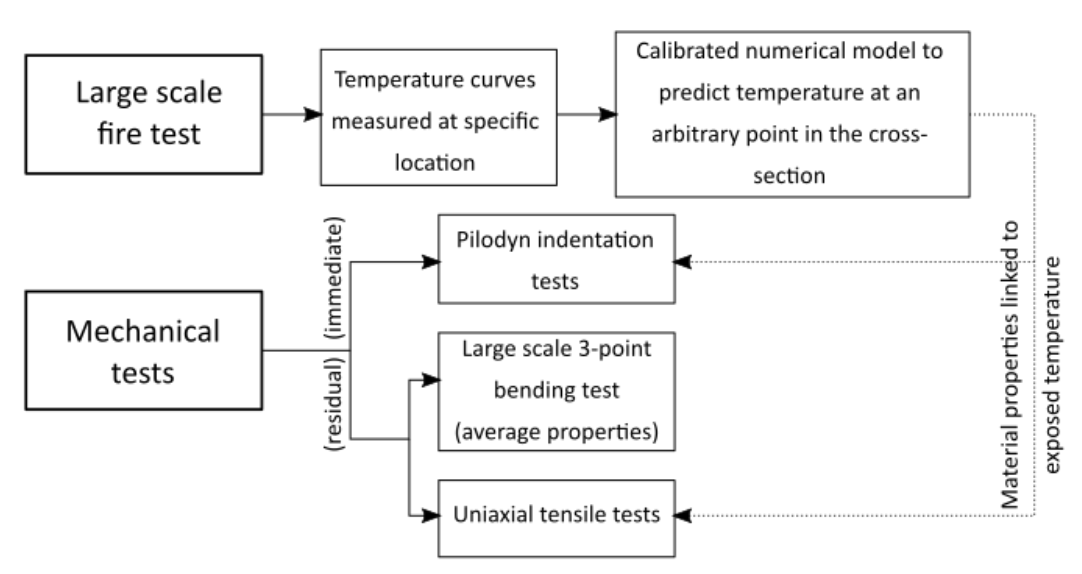

Figure 1. A schematic illustration of individual methods and their connectivity to achieve the paper objectives.

Because of a relatively short duration of fire experiments not exceeding one hour, the influence of exposure-time on the reduction of mechanical properties is not an issue and the interested reader may consult, e.g., $[1,8,10,14,15]$.

\section{Materials and Methods}

To open the discussion on residual mechanical properties of spruce (Picea abies) wood specimens loaded initially by fire, we revisit the fire experiments on GLT beams described originally in [16]. We aim at predicting the temperature profiles within the beam crosssection for all examined fire scenarios to provide the stepping stone for the derivation of residual properties experimentally from large-scale three-point bending (3PB) tests and standard small-scale tensile tests, recall Figure 1. In the latter case, the predicted temperature profile will allow us to assign the corresponding temperature to each specimen produced directly from the fire-exposed GLT beams.

The proposed numerical-experimental program is organized as follows. We begin in Section 2.1 with the discussion on large-scale fire tests to deliver the input data in terms of the loading temperature curves and the measured evolution of temperatures at specific locations needed in the formulation, calibration and validation of the numerical model briefly outlined in Section 2.2. The description of all experimental methods to acquire the desired mechanical properties is provided next in Sections 2.3. To guarantee clarity of the presented workflow we will organize the presentation of the associated results in Section 3 accordingly. 


\subsection{Large-Scale Fire Test}

Two groups of GLT beams with the same span $L=2400 \mathrm{~mm}$ and height $h=320 \mathrm{~mm}$ but variable width $b=100 \mathrm{~mm}$ (Group 1: beams S1-S8) and $b=160 \mathrm{~mm}$ (Group 2: beams S9-S16) were tested. Each beam, made of eight rows of lamellae connected vertically by melamine-urea-formaldehyde glue and horizontally by finger joints, was graded as GL24h. Average initial moisture content of all beams before testing was found around $10 \%$ combining both the standard gravimetric measurements on control samples and measurements carried out directly on beams using the capacitive hygrometer Ahlborn Almemo FHA 696 MF.

The adopted furnace was medium size with inner dimensions of $1.8 \mathrm{~m} \times 1 \mathrm{~m} \times 1 \mathrm{~m}$, enabling us to test two beams simultaneously. One beam in each set (even-numbered) was instrumented with 11 thermocouples placed in the drilled holes with the locations varying both in depth and width of the cross-section along the midspan of the beam, see Figure 2a. These thermocouples were of the type $\mathrm{K}$ with the sensitivity of $40 \mu \mathrm{V} /{ }^{\circ} \mathrm{C}$. The adopted probes allowed for measuring temperatures up to $704{ }^{\circ} \mathrm{C}$ with the precision of one significant digit. The measurements were collected every $3 \mathrm{~s}$. The other beam (oddnumbered), not weakened by the drilled holes, was used later in the mechanical three-point bending ( $3 \mathrm{~PB}$ ) tests to acquire its residual bending stiffness and load-bearing capacity. The heat was supplied by two gas burners located at the bottom of the furnace according to the Set temperature curves representing a standard fire test. The actual temperature in the furnace, henceforth denoted as the furnace temperature, was measured by an additional thermocouple placed near the bottom of the furnace, approximately at the level of the burners. A considerable deviation of the two sets of temperature curves, particularly at an early stage, was observed in all experiments. This promoted the furnace temperature curves plotted in Figure $2 \mathrm{~b}$ to be used as the loading curves in numerical simulations. These curves correspond to four fire scenarios differing principally in exposure time-20, 30, 40, $60 \mathrm{~min}$.

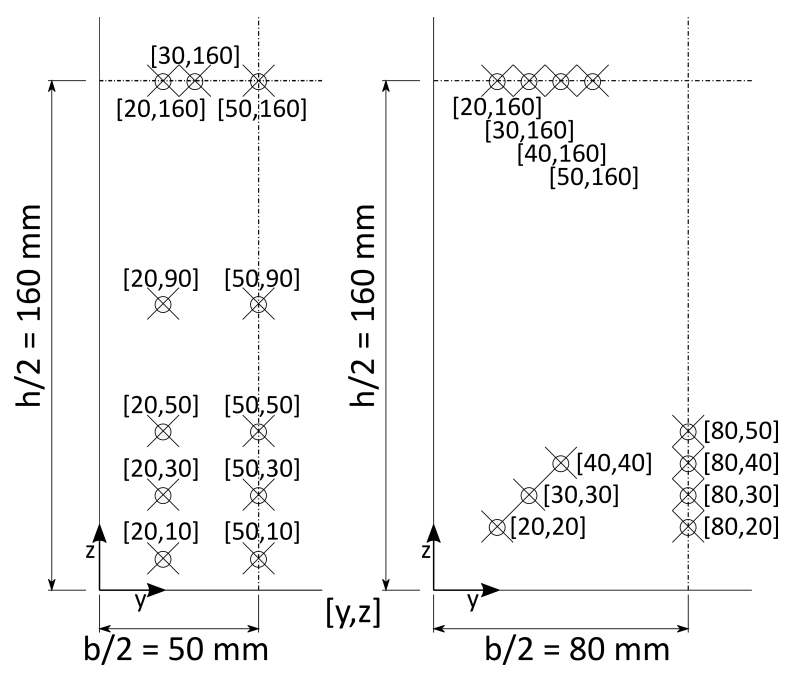

(a)

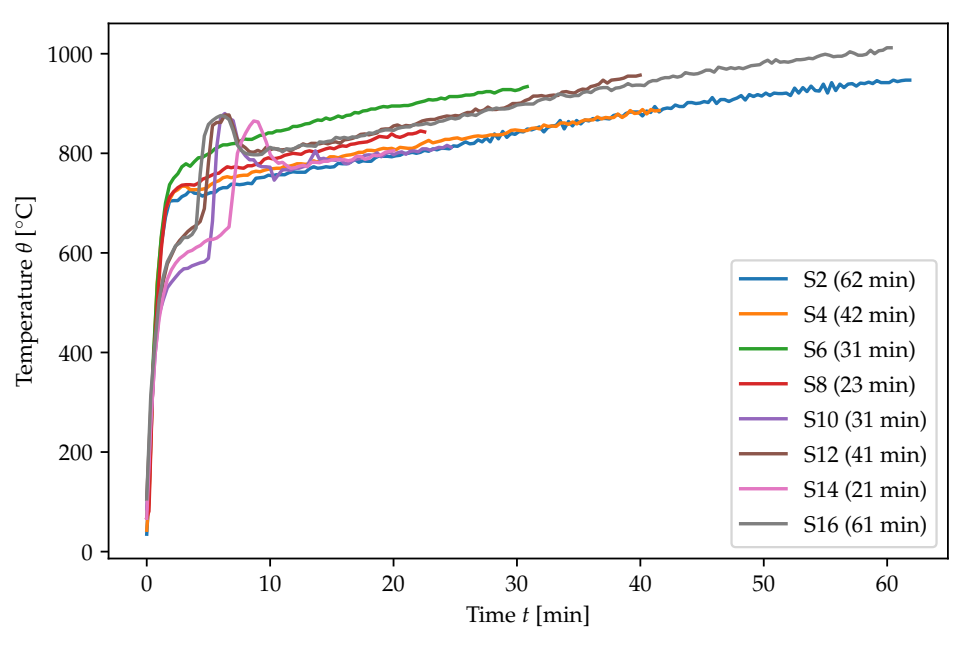

(b)

Figure 2. (a) Position of thermocouples within both cross-sections (Groups 1 and 2), (b) Furnace temperature curves.

\subsection{Numerical Model to Reconstruct Temperature Profiles}

A negative impact of moisture on mechanical properties of wood is generally accepted $([6,8,15]$, to cite a few). It thus appears natural to study the effect of temperature and moisture simultaneously. This is supported by observations suggesting a significant increase in moisture content in inner sections remaining at a low temperature [17]. At normal conditions, the modeling of simultaneous heat and moisture transport is well understood, albeit the need for non-Fickian formulation $[5,18,19]$. However, advancement to 
fire conditions requires describing relevant pyrolysis processes which involves a relatively large number of input parameters, see e.g., [20,21].

Although certainly useful when addressing immediate material properties during fire, such complex models seem unnecessary when limiting attention to residual properties. These are controlled merely by the witnessed temperature because irrecoverable processes near the char layer take place at very low moisture content and in the central part of the beam cross-section at temperatures well below $100{ }^{\circ} \mathrm{C}$ all processes are fully recoverable. Because studying the residual properties is also the aim of the present study, we proceed in the footsteps of [22] and adopt a simple heat transfer model.

We start from the balance equation given by

$$
\rho(\theta) \mathcal{c}(\theta) \frac{\partial \theta}{\partial t}(\mathbf{x}, t)=\nabla^{\top}(\lambda(\theta) \nabla \theta(\mathbf{x}, t))=0, \quad \mathbf{x}, t \in D \times\left(0, t_{s}\right),
$$

where $\theta\left[{ }^{\circ} \mathrm{C}\right]$ is the temperature inside the open bounded domain $D \subseteq \mathbb{R}^{3}, \rho\left[\mathrm{kgm}^{-3}\right]$ is the volumetric mass density, $c\left[\mathrm{JKg}^{-1} \mathrm{~K}^{-1}\right]$ is the specific heat capacity, $\lambda\left[\mathrm{Wm}^{-1} \mathrm{~K}^{-1}\right]$ is the thermal conductivity, and $t_{s}[\mathrm{~s}]$ is the final time of the simulation. The mass density $\rho(\theta)$ and the specific heat capacity $c(\theta)$ are assumed in the form

$$
\rho(\theta)=\rho_{\text {in }} r_{\rho}(\theta), \quad c(\theta)=c_{\text {in }} r_{c}(\theta),
$$

where $r_{\rho}[-]$ and $r_{c}[-]$ are the dimensionless density and specific heat capacity ratios, respectively, both nonlinearly dependent on temperature, and $\rho_{\text {in }}$ is the constant value of the mass density set to $\rho_{\text {in }}=\rho_{\text {air }-d r y}=410\left[\mathrm{kgm}^{-3}\right]$. The assumed variations of $r_{\rho}, r_{c}$, and $\lambda$ with temperature are plotted in Figure 3 .

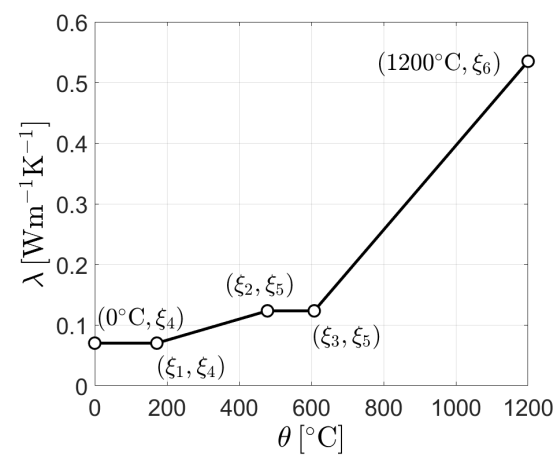

(a)

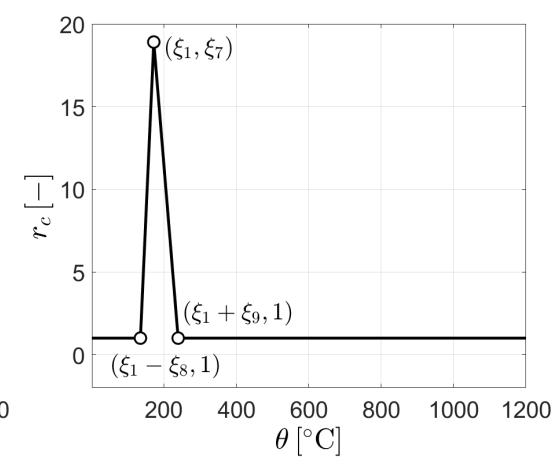

(b)

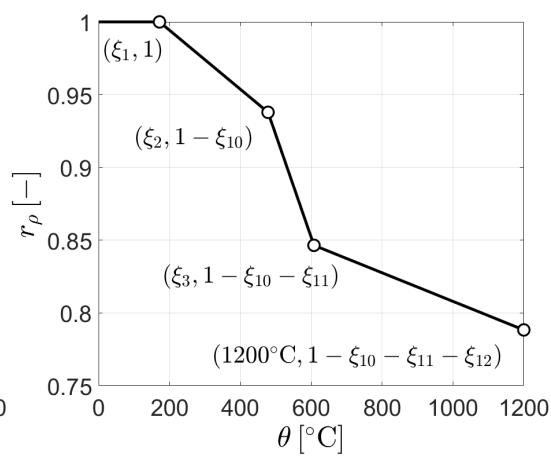

(c)

Figure 3. Parametrized thermal properties as a function of temperature and $\xi$-parameters: (a) thermal conductivity, (b) specific heat capacity ratio, (c) density ratio.

Parameters $\xi_{1}-\xi_{13}$ were found from the stochastic optimization with the help of Bayesian inference by matching numerical predictions and measured temperature profiles. Therein, only the beams S4, S6, and S8 from Group 1 were used excluding the beam S2, where the temperature records showed unacceptable fluctuations caused by malfunctioning of thermocouples. The mean values accepted in this study are listed in Table 1 also identifying the parametrized temperature-dependent relations of the model parameters. Optimal relations are replotted for clarity in Figure 4. 
Table 1. Definition of $\xi$-parameters introduced into the temperature-dependent relations of thermal properties.

\begin{tabular}{llll}
\hline Symbol & Description & Value & Unit \\
\hline$\xi_{1}$ & & 149.4 & {$\left[{ }^{\circ} \mathrm{C}\right]$} \\
$\xi_{2}$ & & 474.7 & {$\left[{ }^{\circ} \mathrm{C}\right]$} \\
$\xi_{3}$ & 611.1 & {$\left[{ }^{\circ} \mathrm{C}\right]$} \\
$\xi_{4}$ & {$\left[\lambda(0), \lambda\left(\xi_{1}\right)\right]$} & 0.10 & {$\left[\mathrm{Wm}^{-1} \mathrm{~K}^{-1}\right]$} \\
$\xi_{5}$ & {$\left[\lambda\left(\xi_{2}\right), \lambda\left(\xi_{3}\right)\right]$} & 0.10 & {$\left[\mathrm{Wm}^{-1} \mathrm{~K}^{-1}\right]$} \\
$\xi_{6}$ & $\lambda\left(1200{ }^{\circ} \mathrm{C}\right)$ & 0.54 & {$\left[\mathrm{Wm}^{-1} \mathrm{~K}^{-1}\right]$} \\
$\xi_{7}$ & $r_{c}\left(\xi_{1}\right)$ & 15.0 & {$[-]$} \\
$\xi_{8}$ & $r_{c}\left(\xi_{1}-\xi_{8}\right)=1$ & 43.9 & {$\left[{ }^{\circ} \mathrm{C}\right]$} \\
$\xi_{9}$ & $r_{c}\left(\xi_{1}+\xi_{9}\right)=1$ & 68.9 & {$\left[{ }^{\circ} \mathrm{C}\right]$} \\
$\xi_{10}$ & $r_{\rho}\left(\xi_{2}\right)=1-\xi_{10}$ & 0.05 & {$[-]$} \\
$\xi_{11}$ & $r_{\rho}\left(\xi_{3}\right)=1-\xi_{10}-\xi_{11}$ & 0.08 & {$[-]$} \\
$\xi_{12}$ & $r_{\rho}\left(1200{ }^{\circ} \mathrm{C}\right)=1-\xi_{10}-\xi_{11}-\xi_{12}$ & 0.07 & {$[-]$} \\
$\xi_{13}$ & $c_{\text {in }}$ & 978.6 & {$\left[\mathrm{Jkg}^{-1} \mathrm{~K}^{-1}\right]$} \\
\hline
\end{tabular}

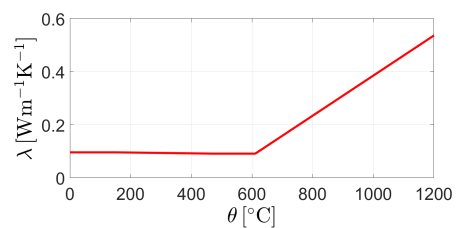

(a)

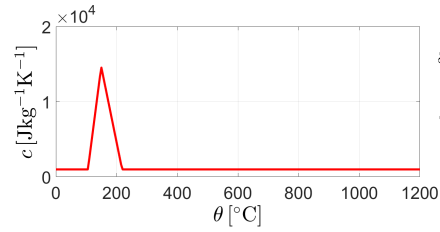

(b)

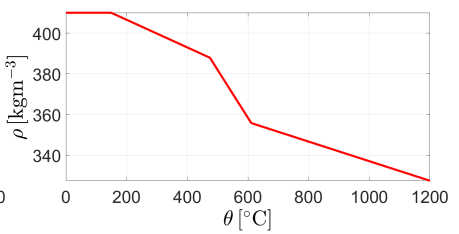

(c)

Figure 4. Optimal thermal properties derived from Bayesian calibration: (a) thermal conductivity, (b) specific heat capacity, (c) density.

To complement the strong formulation we introduce the Robin (radiation) boundary condition on $\partial D$ as

$$
-\boldsymbol{n}^{\top}(\boldsymbol{\lambda}(\theta) \nabla \theta(\mathbf{x}, t))=\alpha\left(\theta(\mathbf{x}, t)-\theta_{\infty}(\mathbf{x}, t)\right)+e \sigma\left(\theta^{4}(\mathbf{x}, t)-\theta_{\infty}^{4}(\mathbf{x}, t)\right), \mathbf{x} \in \partial D,
$$

where $\theta_{\infty}$ is the ambient temperature, $\alpha\left[\mathrm{Wm}^{-2} \mathrm{~K}^{-1}\right]$ is the heat transfer coefficient, $e[-]$ is the emissivity of the surface, and $\sigma=5.67 \times 10^{-8} \mathrm{Wm}^{-2} \mathrm{~K}^{-4}$ is the Stefan-Boltzmann constant. Although the mean value of $\alpha=22 \mathrm{Wm}^{-2} \mathrm{~K}^{-1}$ follows from the calibration procedure, the value of $e=0.8$ is assumed constant independent of fire conditions.

The temperature profiles for individual furnace temperature curves were derived using the one-dimensional (1D) version of the finite element method (Please note that specimens for tensile experiments discussed in Section 2.3.3 were extracted from parts in the vicinity of the beam mid-axis so not affected by corner roundings. The parameter $\lambda$ in Table 1 then takes the value of $\lambda$ in the direction perpendicular to the grain). In this context, the balanced Equation (1) was first discretized in time using the midpoint integration rule and then introduced into the weak solution. The final system of nonlinear algebraic equations resulting from space discretization was solved incrementally employing the Newton-Raphson iterative method.

\subsection{Mechanical Properties}

A variety of experimental techniques has been examined to assess the residual tensile properties of spruce wood exposed to standard fire tests. The designed experimental program is described next.

\subsubsection{Young's Modulus from Pilodyn Measurements}

An appealing nondestructive experimental technique, which allows for the determination of modulus of elasticity of wood segments already built into an existing structure, exploits macro-indentation. To this end, an indenter of $2.5 \mathrm{~mm}$ in diameter is shot into 
the wood using a Pilodyn device. The longitudinal modulus in the fiber direction in terms of the measured indentation depth $d$ is then provided by the following parametric equation $[3,23]$

$$
E=19.367-0.5641 d
$$

All examined beams were subjected to indentation measurements both before and immediately after the fire test was completed. Unlike the beam in Group 1 (S2-S8), the beams in Group 2 (S10-S16) were mechanically treated prior to indentation using a grinder.

\subsubsection{Bending Modulus of Elasticity and Load-Bearing Capacity from Bending Tests}

To acquire the residual load-bearing capacity, the beams not weakened by the drilled holes (odd-numbered) were loaded in three-point bending. The experimental set-up is shown in Figure 5a. To avoid any normal compressive force, the beams were supported by a roller on both sides approximately $5 \mathrm{~cm}$ away from the free ends. At supports the beams were constrained against tilting. All beams were loaded in the displacement control regime with a loading rate of $0.02 \mathrm{~mm} \mathrm{~s}^{-1}$ until failure. The maximum displacement in the middle part of the beam was recorded via a string potentiometer. Owing to a beam cross-section irregularity a distribution element (steel plate-beams S9, S11, S13, channel section plate-beams S1, S3, S5, S7, S15) was used to ensure a reliable transfer of the load into the beam.

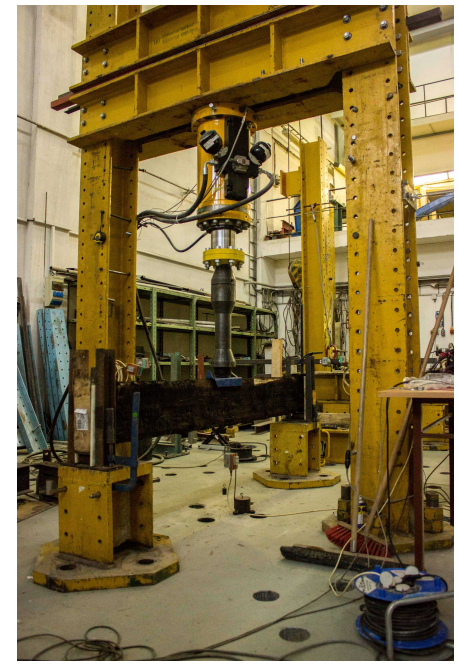

(a)

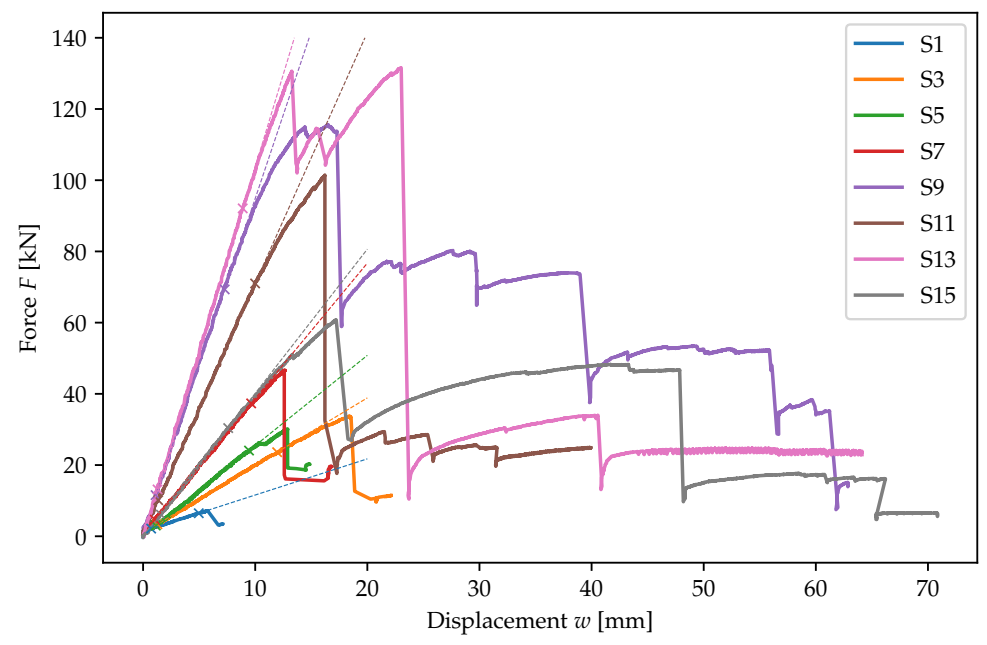

(b)

Figure 5. (a) Experimental set-up of three-point bending test, (b) Load-displacement curves.

The resulting load-displacement curves are plotted in Figure $5 \mathrm{~b}$ indicating also the initial elastic branch. To estimate the Young's modulus in bending, the pairs of forcedeflection points $F^{i}-w_{\max }^{i}$ within the initial linear part of the load-displacement curve was first fitted to a line $F=k w_{\max }+q$. The slope $k$ was then substituted into a well-known equation for the maximum deflection in 3 PB test to get

$$
E_{b}=\frac{1}{\left(b-d_{e f f}\right)\left(h-d_{e f f}\right)^{3}} \frac{k L^{3}}{4}, \quad d_{e f f}=2\left(d_{c h a r}+d_{0}\right),
$$

where $b, h, L$ are the beam width, height, and span, respectively, and $d_{e f f}$ represents an effective charring depth derived from a charring depth $d_{\text {char }}$, here obtained from image analysis carried out in [16] and a zero-strength layer $d_{0}$ set for simplicity to $7 \mathrm{~mm}$ in the present study [24]. Please note that the value of $d_{0}$ is typically a function of specific conditions including the fire scenario and duration as well as the beam geometry $[11,13,16]$ and may considerably deviate from this value. 
To provide a quick estimate of the tensile strength in bending calls for some simplifications. In particular, we adopt the peak force $F_{\max }$ associated with the first failure and assume a linear through-thickness variation of the axial stress thus neglecting all nonlinear effects prior to reaching this point. The maximum allowable stress to avoid fracture then reads

$$
\sigma_{b}^{\max }=\frac{3 F_{\max } L}{2\left(b-d_{e f f}\right)\left(h-d_{e f f}\right)^{2}} .
$$

\subsubsection{Young's Modulus and Strength Along Grain from Tensile Experiments}

An initiative study on this subject is presented in [25] focusing on wood variability and the effect of growth discontinuities. In the present study, we proceeded in the similar way but attempted to also address the regions right next to the charring front where permanent changes to wood properties caused by elevated temperature might be expected. Similarly to [25], small dog-bone specimens $5 \mathrm{~mm}$ in thickness were produced from about $24 \mathrm{~cm}$ long segments cut from four GLT beams exposed to fire (Group 2-beams S10, S12, S14, S16-3 segments from each beam located in the midspan), see Figure 6. As also illustrated in Figure 6, the specimens in Figure 7 were extracted across the width of the beam crosssection from the lamellae with a prevailing 1D heat flow starting as close as possible to the outline of the residual cross-section. The lamellae affected by rounding of corners and those covered by the Sibral blanket, the hatched lamellae in Figure 6, were not considered for the preparation of specimens (see ahead Figure 9).

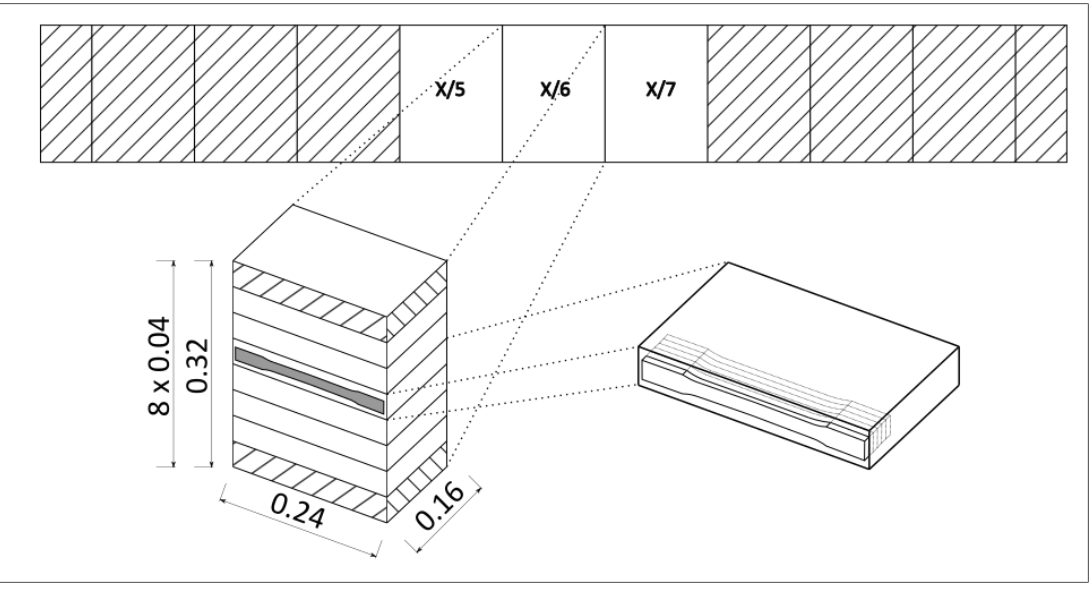

Figure 6. Preparation of specimens.

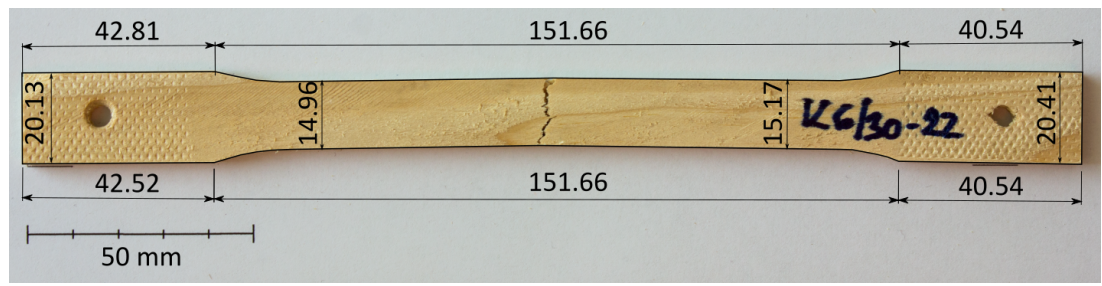

(a)

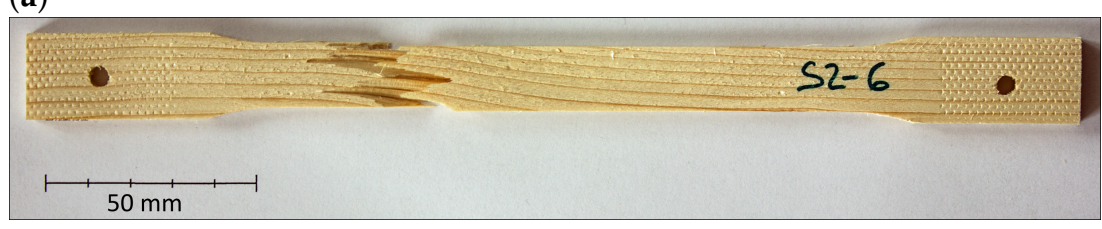

(b)

Figure 7. Specimen geometry: (a) failure across the grain (ideal test-category A), (b) failure along the grain (ideal test-category A). 
Altogether, 220 specimens were prepared and tested in the displacement control regime using the MTS Alliance $30 \mathrm{kN}$ electromechanical testing machine equipped with $30 \mathrm{kN}$ load cell. The rate of loading was set to $0.0125 \mathrm{mms}^{-1}$. A standard $100 \mathrm{~mm}$ long extensometer was used to monitor the strain.

In analogy to [25], the damaged specimens were further categorized according to the type and position of the crack. When the crack developed in the midsection of the specimen, typically along or across the fibers, in clear wood, the test was considered ideal and labeled as category A, see Figure 7. The second category of tests B contains the results from all tests thus also involving a certain type of defect at failure or the crack appearing outside the midsection, typically in the gripping area as illustrated in Figure 8.

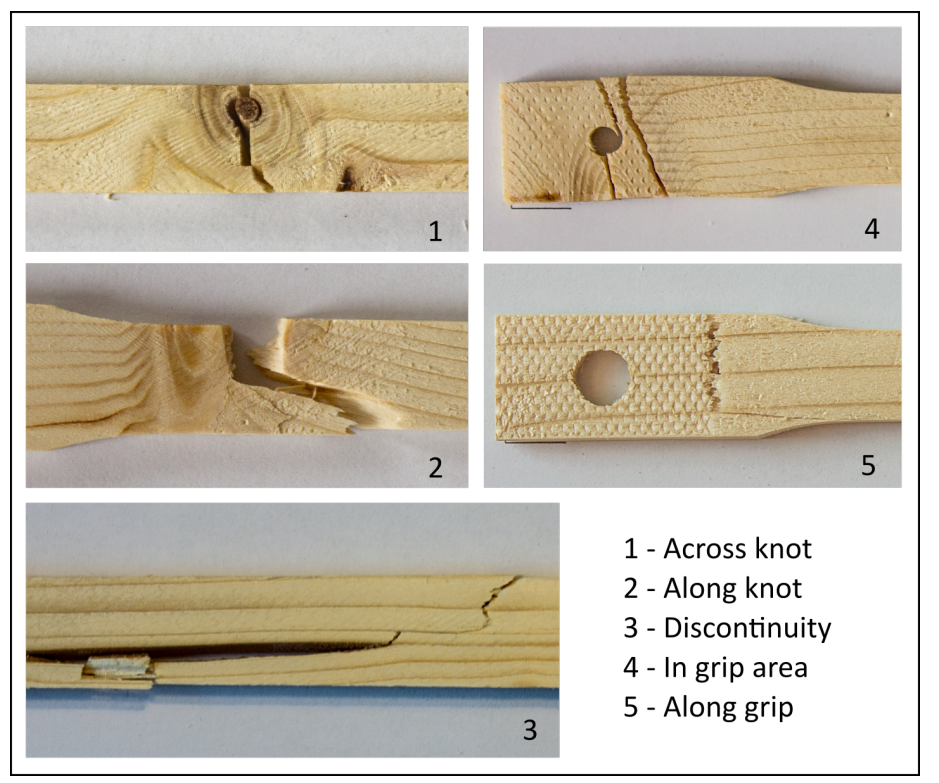

Figure 8. Failure types excluded from category A.

\section{Results}

Hereinafter, we summarize all the numerical and experimental predictions obtained via the methods described in Section 2 maintaining the same order of corresponding subsections. Therefore, we start from the measured temperature curves which not only provide a direct notion of the evolution of temperature in time within the cross-section (Section 3.1), but allow us to also validate the temperature profile predicted numerically (Section 3.2). With these profiles at hand the evaluation of mechanical tests towards the residual properties (Sections 3.3), becomes straightforward.

\subsection{Large-Scale Fire Tests}

The essential information regarding the determination of residual properties is the knowledge of the final temperature profile within the cross-section. This requirement immediately calls for numerical predictions leaving the temperature curves determined experimentally at a priori selected points only, recall the distribution of thermocouples in Figure 2a, as a tool for either model calibration or validation of numerical predictions.

These specific results are displayed in Figure 9. Point out that centering the residual cross-sections within the original outline is only approximate and may not fully correspond to the actual locations of thermocouples. The reason for having the cross-section of sample S4 affected by fire at all sides is because of lacking a ceramic blanket Sibral protecting the drilled holes with thermocouples as was the case in the remaining tests. In every case, a rapid decay of temperature towards the inner parts of the cross-section is evident. We revisit this issue later in Section 3.2. 


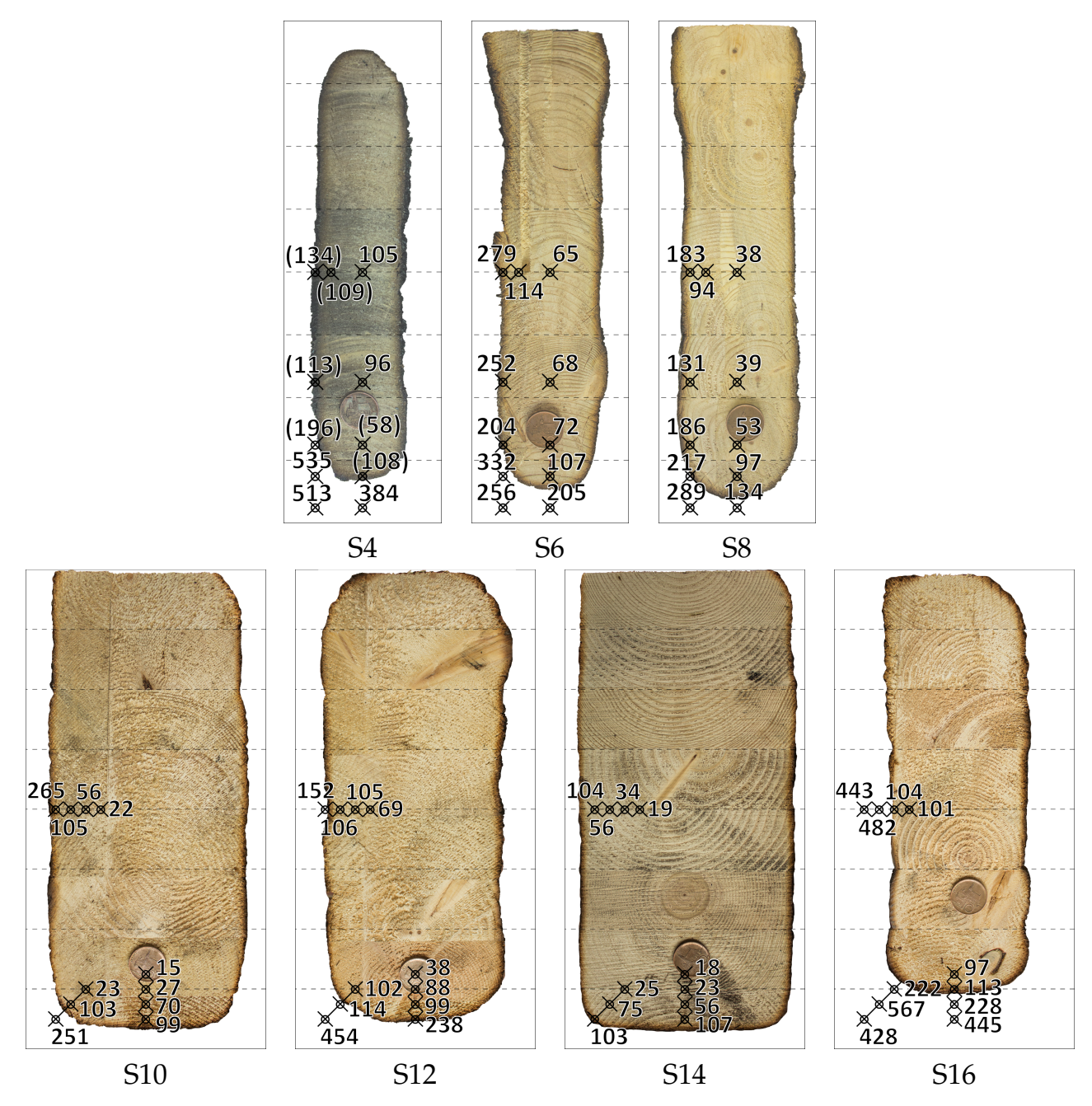

Figure 9. Measured temperatures in residual cross-section at the end of fire tests.

\subsection{Numerical Model to Predict Temperature Profiles}

The one-dimensional simple heat transfer model described in Section 2.2 provides the time evolution of temperature at an arbitrary point in the cross-section. A relevant discussion is presented in Section 3.2.1. It is suggested in Section 3.2.2 that these predictions can further be adopted to estimate the charring depth and the zero strength layer.

\subsubsection{Time Evolution of Temperature Profiles}

Recall that furnace temperatures in Figure $2 \mathrm{~b}$ were adopted as the loading curves in numerical simulations to provide, with the help of radiation conditions (3), the searched through-thickness temperature profiles. The time evolution of these profiles appear in Figure 10. For illustration, only the results corresponding to the shortest and longest fire duration for each group are presented. The differences at the onset of fire test, short times, indicate the effect of a specific fire scenario. One may identify a relatively steep temperature gradient near the charring front (temperate $\theta \approx 300^{\circ} \mathrm{C}$ ) observed already in Figure 9 as well as the influence of fire duration and the dimensions of the beam cross-section. It is seen that for short fires and thick beams the temperature for most of the inner part of the beam cross-section does not even exceed the evaporation temperature of $100^{\circ} \mathrm{C}$, see Figure $10 \mathrm{c}, \mathrm{d}$. This result is not surprising given a relatively low thermal conductivity of wood which kept the inner parts of the beam cross-section at a low temperature for most of the fire tests [6], see also Figure 9. 


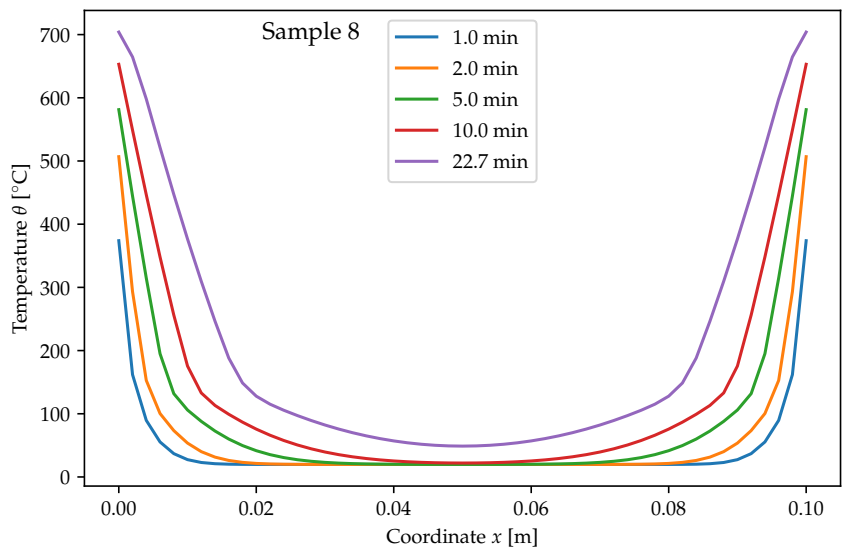

(a)

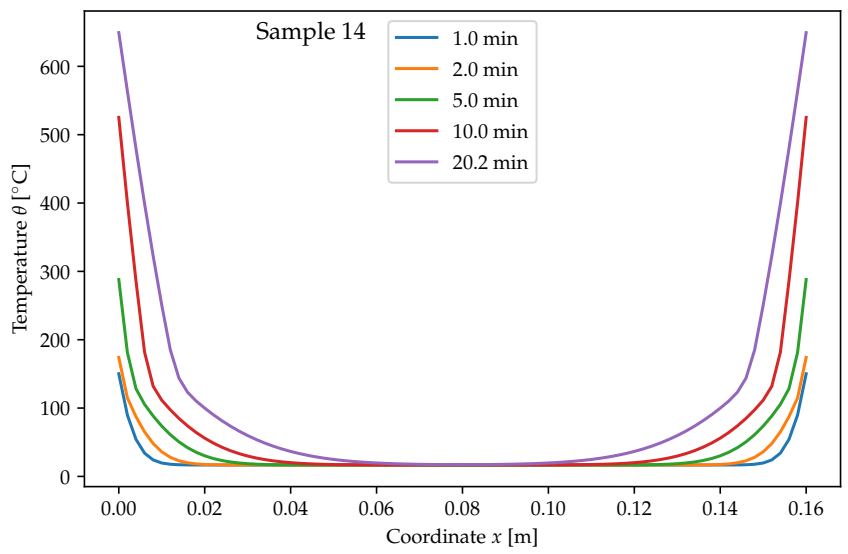

(c)

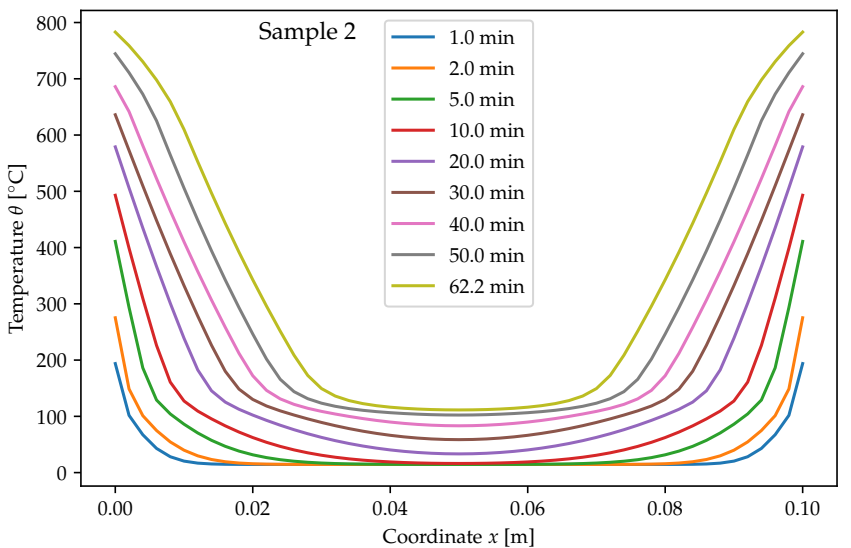

(b)

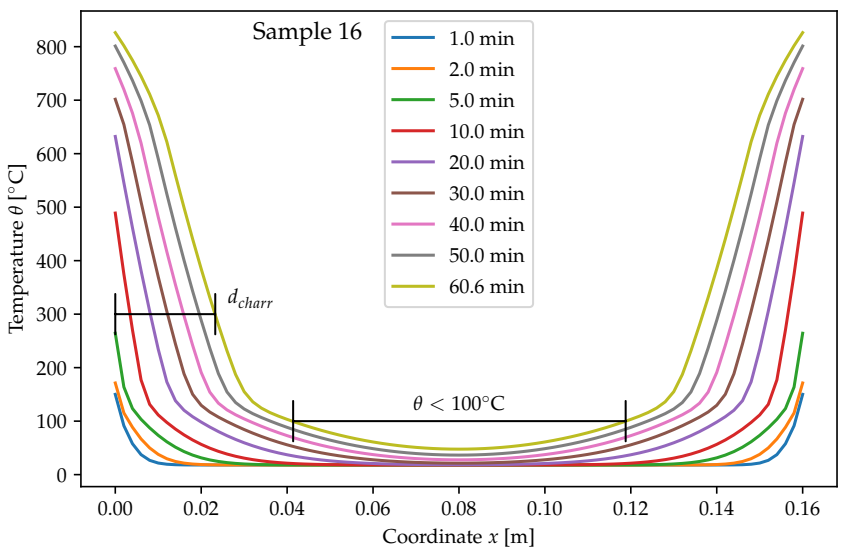

(d)

Figure 10. Temperature profiles for the selected beams: (a) S8 $(b=100 \mathrm{~mm}), t=22.7 \mathrm{~min}$, (b) S2 $(b=100 \mathrm{~mm}), t=62 \mathrm{~min}$, (c) S14 ( $b=160 \mathrm{~mm}), t=20.2 \mathrm{~min},(\mathrm{~d}) \mathrm{S} 16(b=160 \mathrm{~mm}), t=60.6 \mathrm{~min}$.

\subsubsection{Temperature Profiles in Residual Cross-Section}

It is often assumed that the residual cross-section experiences temperatures below $300{ }^{\circ} \mathrm{C}$, where $\theta=300{ }^{\circ} \mathrm{C}$ indicates the charring front. Therefore, the variation of temperature in the residual cross-section at the end of fire can be obtained from the final curves in Figure 11 considering the part passing the charring depth $d_{\text {char }}\left(\theta<300^{\circ} \mathrm{C}\right)$ only, i.e., the abscissa $\bar{x}=x-d_{\text {char }}$ where $x$ is measured from the original beam outline, recall Figure 10 .

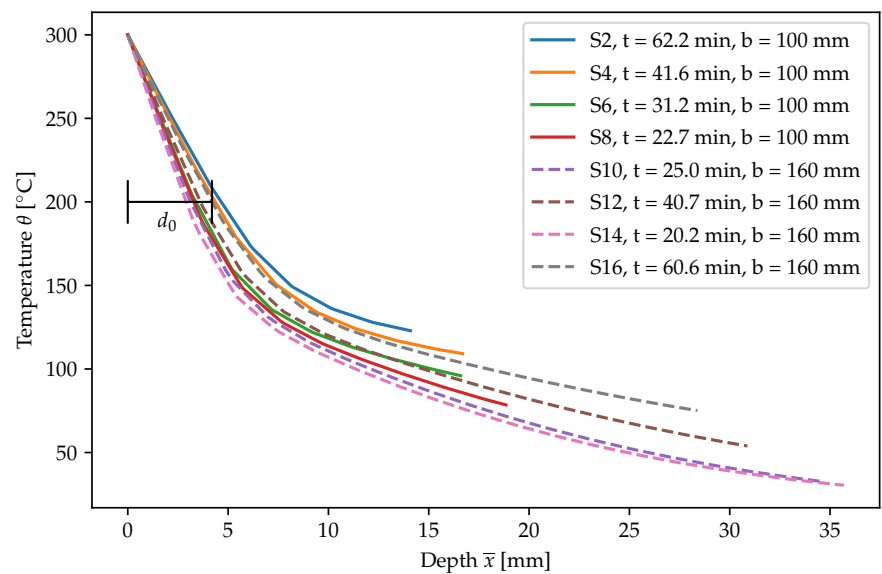

Figure 11. Temperature decay in residual cross-section. 
As one would expect, the steepest temperature gradients are observed for short fires as there was not enough time to warm up the beam cross-sections. This is also why the slowest temperature reduction towards the inner part of the beam cross-section is found for longer times and thin cross-sections as was already indicated in Figure 10. Assuming that the mechanical properties are recoverable below the temperature $\theta=200{ }^{\circ} \mathrm{C}$ the curves in Figure 11 could be further used to estimate, conservatively, the zero-strength layer $d_{0}$ in which both the stiffness and strength are considered equal to zero $[13,26,27]$. Similarly, linking the charring front with the temperature $\theta=300{ }^{\circ} \mathrm{C}$ provides the estimates of charring depth $d_{\text {char }}$. In Figure 10d, one particular example is shown for the beam S16. From that, the two parameters $d_{0}, d_{\text {char }}$ show a clear dependence on fire scenario, exposure time, and cross-sectional characteristics. This may raise a question on the adequacy of simple charring rate models attempting to predict the evolution of charring depth by a constant value of the charring rate $\beta$.

To close the discussion on numerical predictions, one may wish to compare the theoretical values in Figure 11 with those in Figure 9 obtained experimentally. Given the fact that only the beams from Group $1(S 4, S 6, S 8)$ were used to calibrate the model with the attempt to yield a unique set of parameters regardless of the actual fire, the agreement is satisfactory.

\subsection{Mechanical Properties}

The results from the Pilodyn measurements of longitudinal Young's modulus (Section 3.3.1), large three-point bending tests (Section 3.3.2), and standard tensile tests (Section 3.3.3) are compared. The overarching objective is to connect the mechanical properties of individual specimens with the temperature profiles presented in Section 3.2.

\subsubsection{Young's Modulus from Pilodyn Measurements}

Although emphasis is on the determination of residual properties, we illustrate first the effect of high temperature on immediate Young's modulus to be later compared with the results of tensile tests. The Pilodyn measurements combined with Equation (4) were proposed in Section 2.3.1 to solve this task. Although Equation (4) seems more likely as a useful alternative to a visual inspection when addressing the quality of wood, it still provides a relatively good estimate of the expected range of wood stiffness, especially given a large amount of data one may collect directly on the construction site.

Altogether 640 measurements were initially performed on all tested beams in a regular grid before the fire exposure. The measured depth was substituted into Equation (4) to give the estimate of longitudinal Young's modulus. The corresponding distribution in Figure 12 is labeled as "All before". The same procedure was repeated immediately after completing the fire test. The corresponding histograms, denoted as "S2-S8 after" (105 indents on untreated surface) and "S10-S16 after" (160 indents on grounded surface) to make a link with the two groups of beams, are shown again in Figure 12. The reduction of immediate stiffness because of high temperature is evident. Given the experimental procedure, the immediate properties of layers directly adjacent to charring front at the end of fire test associate with the temperature range of $200-300^{\circ} \mathrm{C}$. 

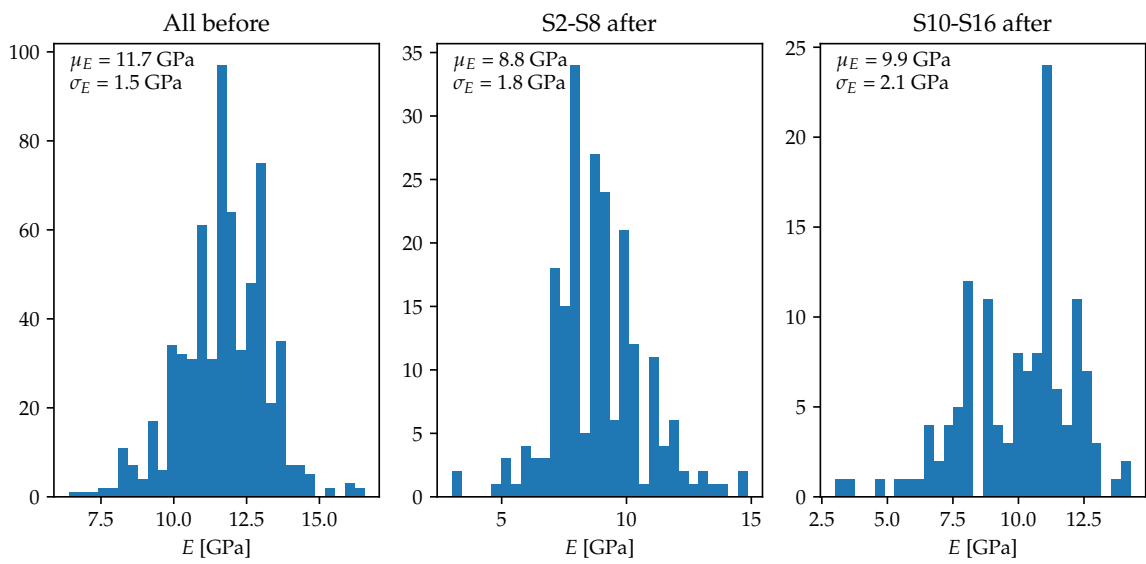

Figure 12. Young's modulus measured by Pilodyn indentation before (All before) and after (Group 1: S2-S8, Group 2: S10-S16) the fire test.

\subsubsection{Bending Modulus of Elasticity and Load-Bearing Capacity from Bending Tests}

The estimate of Young's modulus in bending, Equation (5), and corresponding maximum allowable stress to avoid fracture, Equation (6), are summarized in Table 2. The effect of temperature on residual properties is considerably more pronounced for narrow beams (Group 1) as these are exposed in their inner parts to much higher temperatures compared to wider beams (Group 2) especially for longer exposure times, recall Figures 10 and 11. For beams in Group 2, the sections with temperatures below $100{ }^{\circ} \mathrm{C}$ were found in the range of $75 \%$ to $50 \%$ of the original width depending on the fire duration. Except for the beam S13, where the beam response was significantly affected by a weak zone attributed to a knot cluster on the tension side, the results are fairly consistent. Increasing the width of zero-strength layer $d_{0}$ would thus be incorrect as also supported by the results of the tensile tests presented next.

Table 2. Modulus of elasticity and maximum tensile stress from bending tests.

\begin{tabular}{cccccc}
\hline $\begin{array}{c}\text { Beam } \\
\text { Type }\end{array}$ & $\begin{array}{c}\text { Beam } \\
\text { No. }\end{array}$ & $\begin{array}{c}\boldsymbol{t} \\
{[\mathrm{min}]}\end{array}$ & $\begin{array}{c}\boldsymbol{d}_{\text {char }} \\
{[\mathbf{m m}]}\end{array}$ & $\begin{array}{c}\boldsymbol{E}_{\boldsymbol{b}} \\
{[\mathrm{GPa}]}\end{array}$ & $\begin{array}{c}\sigma_{\boldsymbol{b}}^{\text {max }} \\
{[\mathrm{MPa}]}\end{array}$ \\
\hline Group 1 & 1 & 62.32 & 30.95 & 7.89 & 16.73 \\
& 3 & 42.15 & 20.90 & 6.26 & 36.62 \\
& 5 & 31.40 & 17.86 & 6.81 & 27.04 \\
& 7 & 22.90 & 13.76 & 8.00 & 33.92 \\
\hline Group 2 & 9 & 30.82 & 15.79 & 10.53 & 43.93 \\
& 11 & 40.70 & 21.82 & 10.21 & 47.74 \\
& 13 & 20.24 & 8.42 & 8.86 & 39.90 \\
& 15 & 60.61 & 33.70 & 10.01 & 44.42 \\
\hline
\end{tabular}

\subsubsection{Young's Modulus and Strength Along Grain from Tensile Experiments}

To open this subject, we first recall the results presented in [25]. Therein, only a few samples experienced some level of browning. Therefore, we concentrated merely on the impact of defects rather than temperature. It has been concluded that the wood variability and the effect of growth discontinuities are probably more significant than the effect of elevated temperatures when addressing the residual properties only.

For illustration and for the sake of further comparison we present one particular result, while for more detailed discussion the interested reader is referred to [25]. In particular, the distributions in Figures 13 and 14 distinguish the two categories introduced in Section 2.3.3 (category A-ideal test: 161 specimens, category B-all tests: 366 specimens), also recall Figures 6 and 7. As one would expect, filtering out the observed defects partially reduces a relatively large scatter of the measured data. Nevertheless, the reduction was not so 
pronounced for Young's modulus as for strength for which considering the ideal tests only is essentially inevitable to arrive at meaningful results.

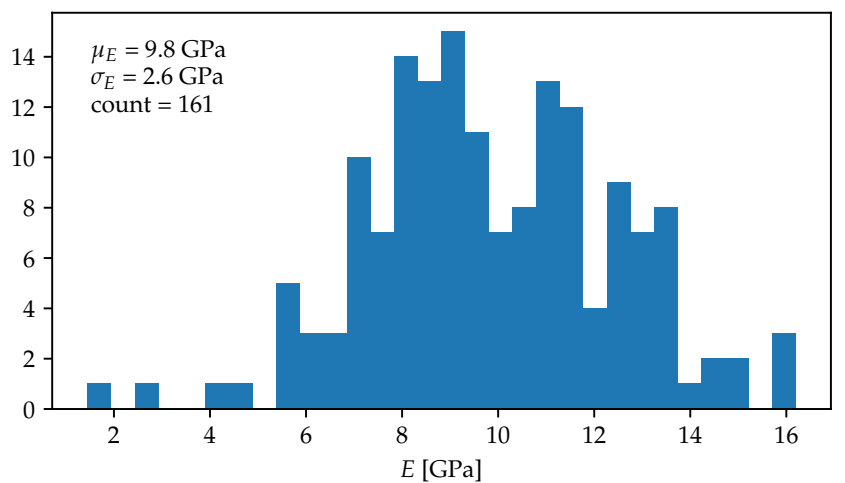

(a)

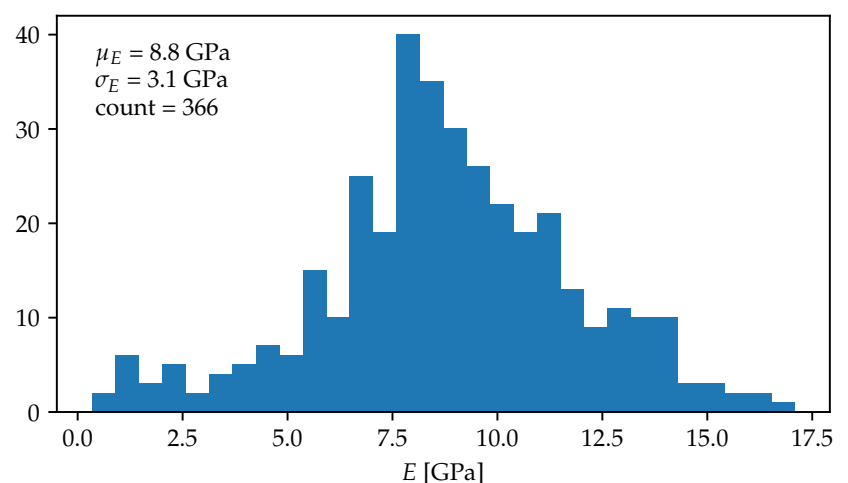

(b)

Figure 13. Distribution of residual Young's modulus obtained from tensile tests on specimens extracted from beams in Group 1: (a) category A, (b) category B.

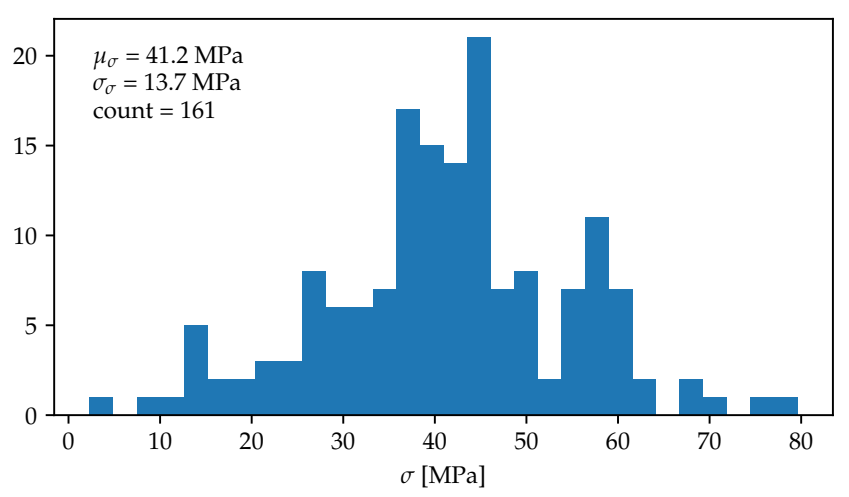

(a)

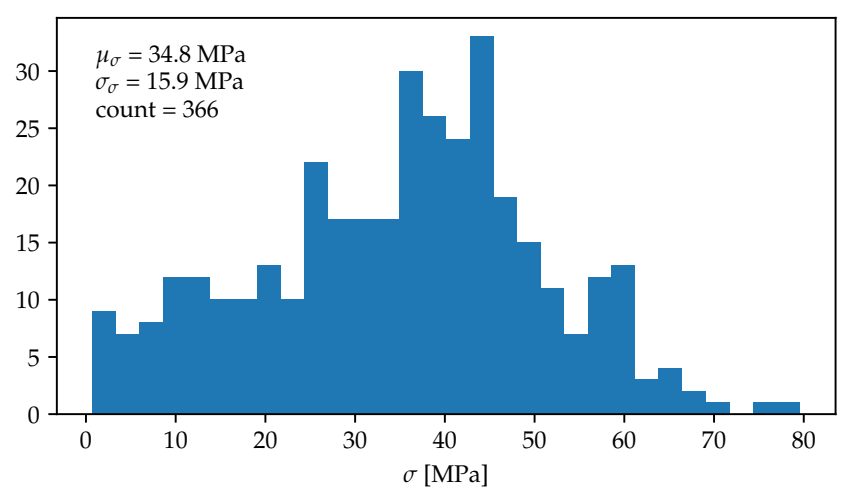

(b)

Figure 14. Distribution of residual tensile strength obtained from tensile tests on specimens extracted from beams in Group 1: (a) category A, (b) category B.

We now turn our attention to a set of experiments where each specimen was assigned a specific temperature predicted by the numerical model based on its location in the beam cross-section. In the remainder, this location is represented by the $\bar{x}$ abscissa introduced in Figure 11. Variation of the residual longitudinal Young's modulus as a function of the maximum temperature the wood was exposed to is shown in Figure 15, distinguishing again the two categories A and B. Each set of specimens from a given fire scenario is identified with the location $\bar{x}$ passing the charring depth and the corresponding temperature. Because of a rapid drop of temperature towards the inner part of the beam cross-section observed in Figure 11, the group of specimens second to the right from the charring front has already experienced a temperature not exceeding much the temperature of $100{ }^{\circ} \mathrm{C}$. Note that the location of this group is well behind the value of the zero-strength layer $d_{0}$ proposed in Eurocode [24]. 


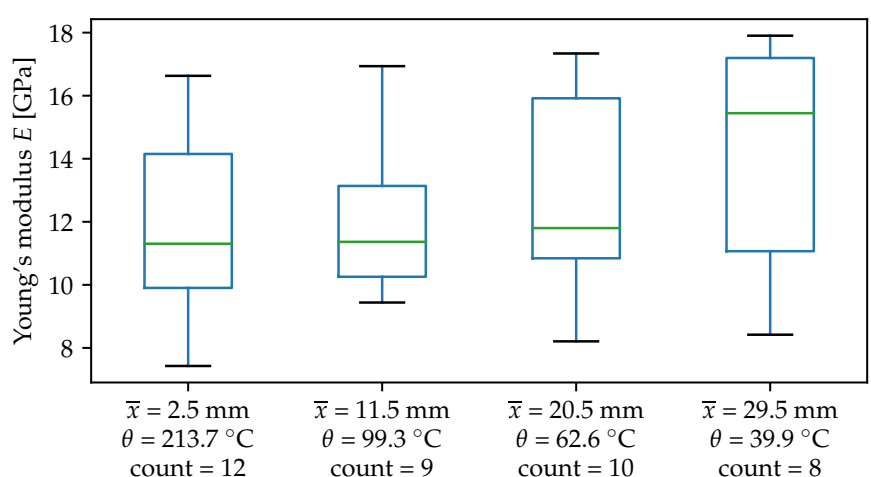

(a)

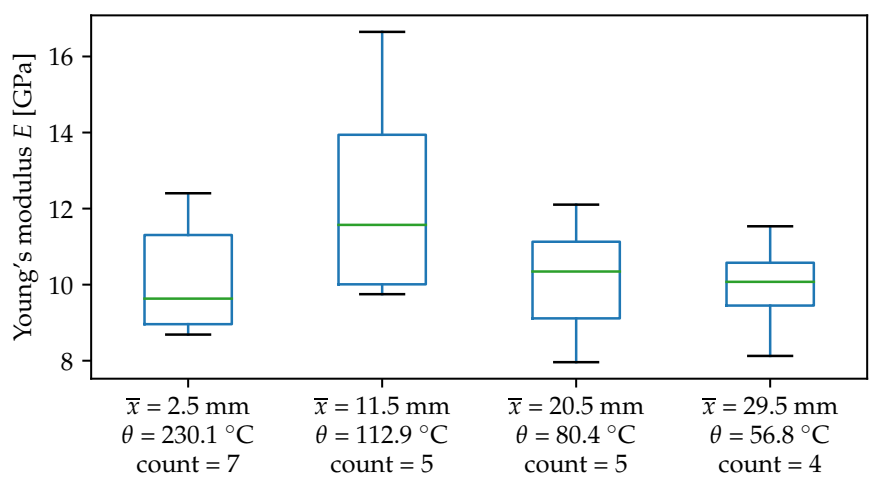

(c)

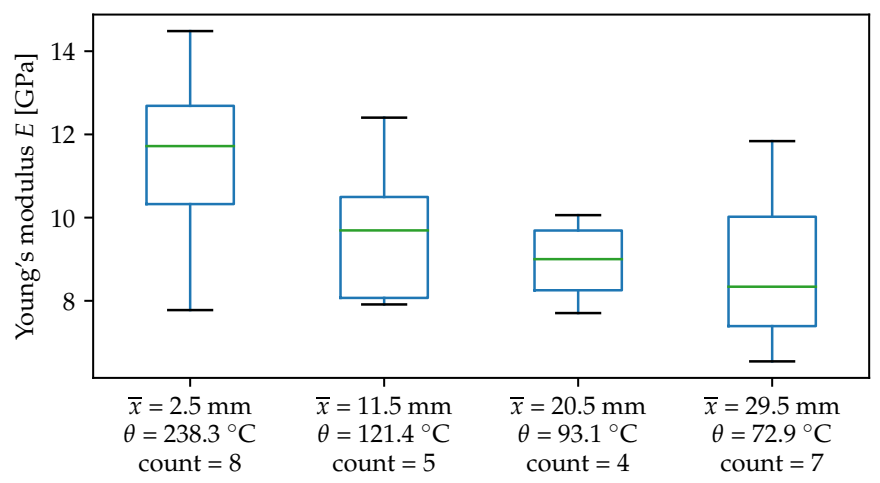

(e)

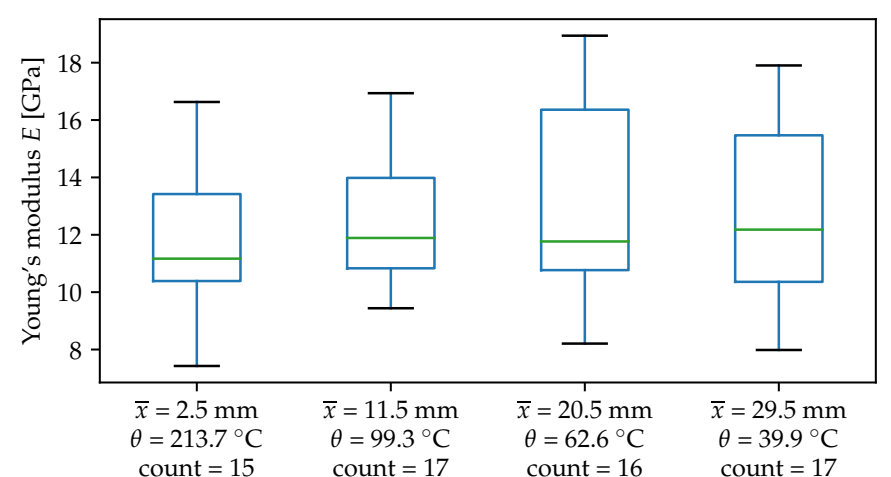

(b)

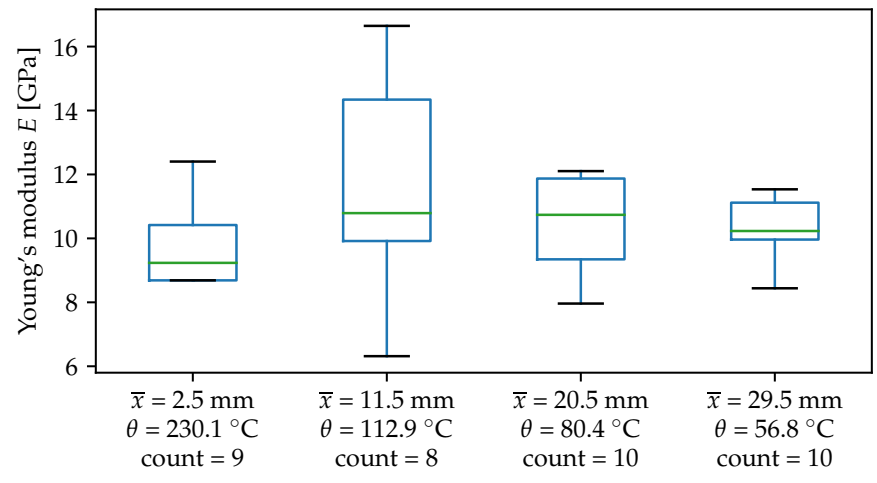

(d)

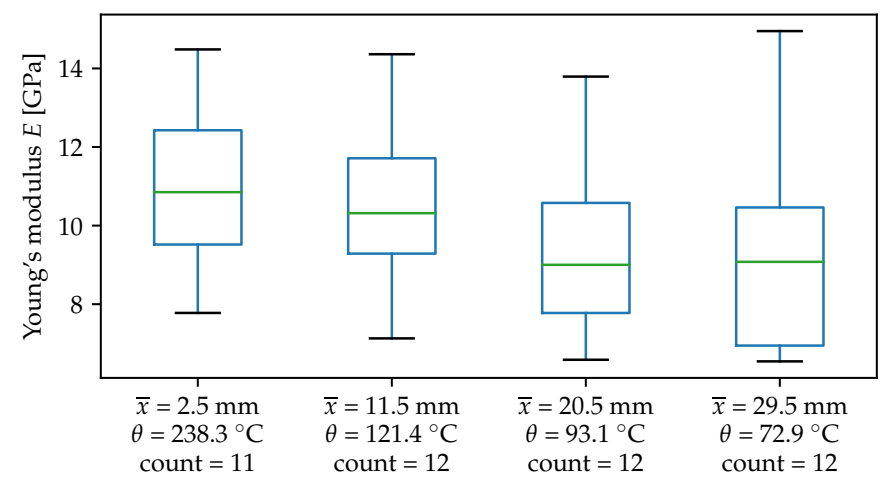

(f)

Figure 15. Young's modulus: (a) S14 (20.24 min, A), (b) S14 (20.24 min, B), (c) S12 (40.70 min, A), (d) S12 (40.70 min, A), (e) S16 (60.61 min, A), (f) S16 (60.61 min, B).

Inspecting the results in Figure 15e,f, one may associate a slight increase in stiffness with the increase of crystallinity due to high temperature. This, however, has not been fully confirmed by other results. There is no observed trend describing the dependence of residual Young's modulus on the temperature, to which the residual beam cross-section was exposed during fire. This is further supported by the scatter plot in Figure 16 suggesting not so much the functional dependency on temperature as an apparent material variability.

What seems to be more affected by an elevated temperature is the tensile strength as evident in Figure 17 (The compressive strength was not examined as the prism specimens extracted from beams would have had too large dimensions to experience a uniform temperature above $100{ }^{\circ} \mathrm{C}$ ). We see that for the longest fire duration, thus also the highest 
temperature in the most prominent layer adjacent to the charring front, the tensile strength dropped down on average below $20 \mathrm{MPa}$. This can most probably be attributed to the permanent changes in microstructure because the moisture content in all specimens at the time of testing was about $9 \%$ and therefore had no particular effect. This finding is supported in Figure 16a showing, apart from an even higher scatter in strength when compared to stiffness, a clear gradual reduction when passing the temperature of $100{ }^{\circ} \mathrm{C}$.

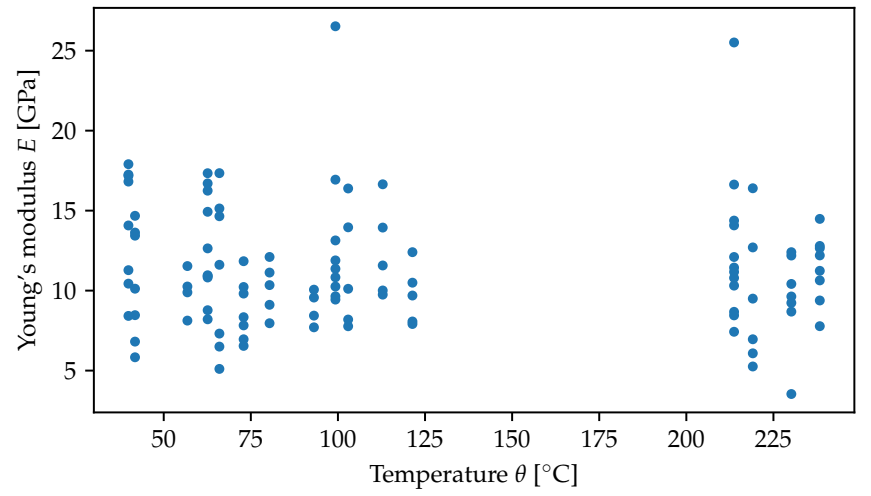

(a)

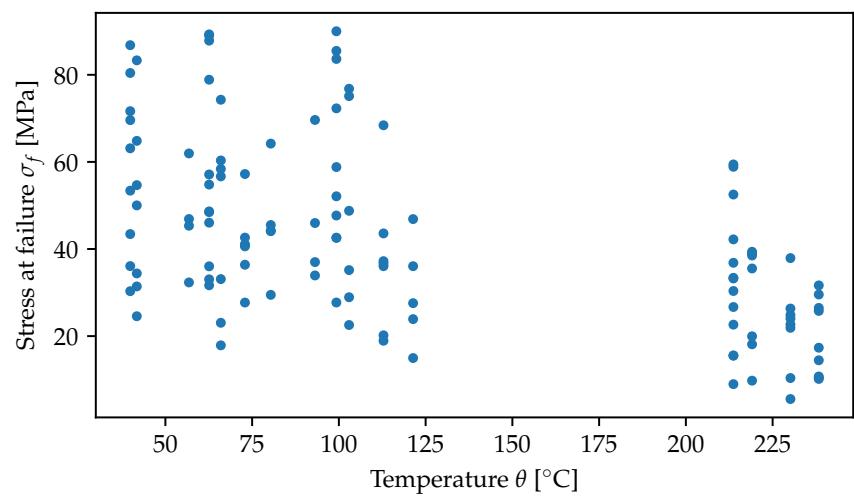

(b)

Figure 16. Scatter plot collecting results from ideal tensile tests (category A): (a) Young's modulus, (b) tensile strength.

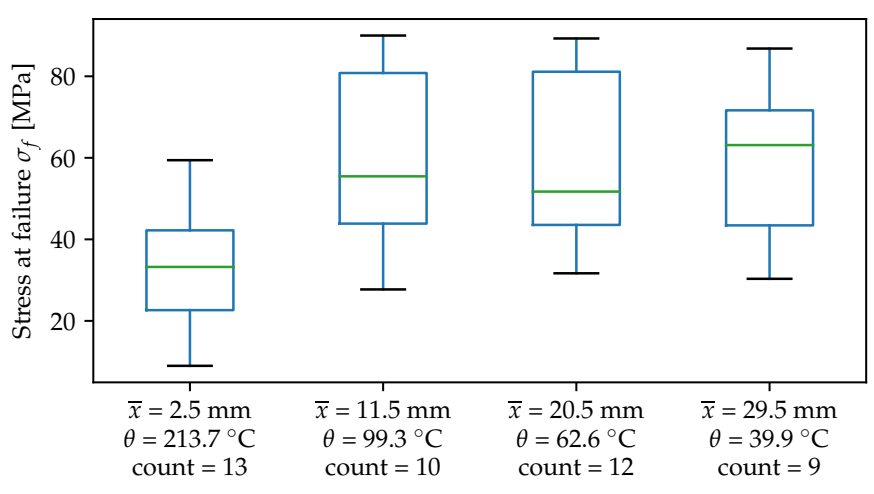

(a)

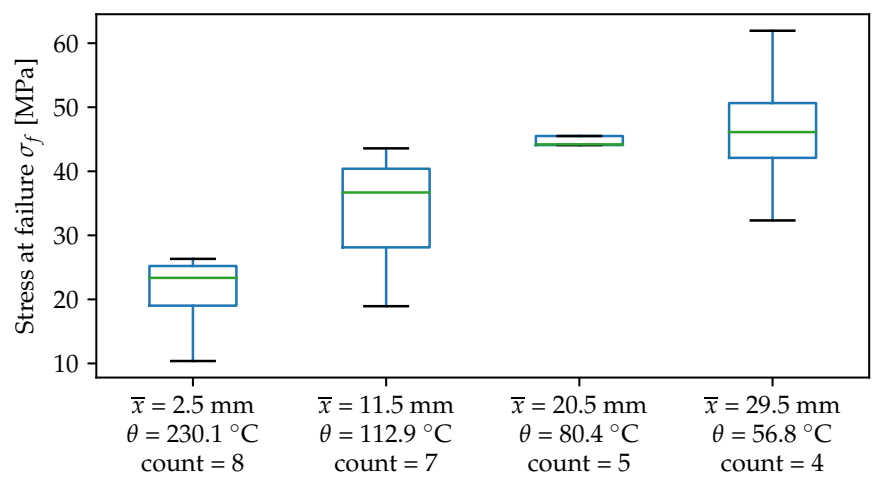

(c)

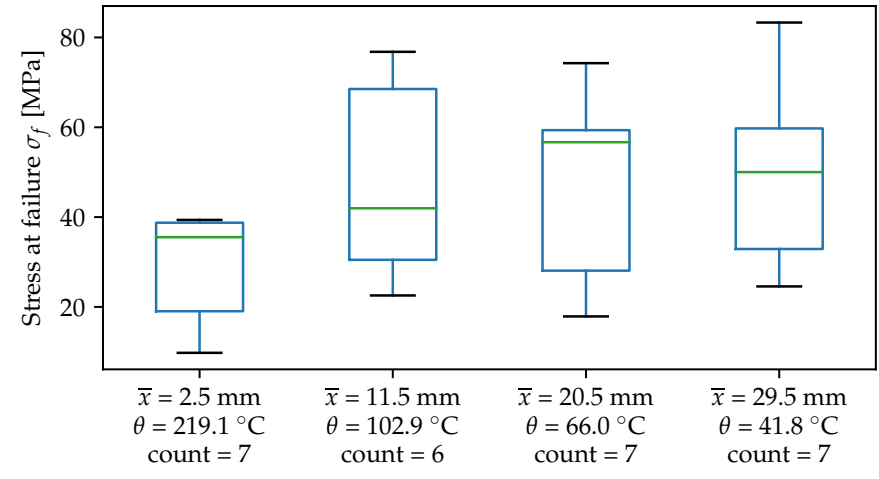

(b)

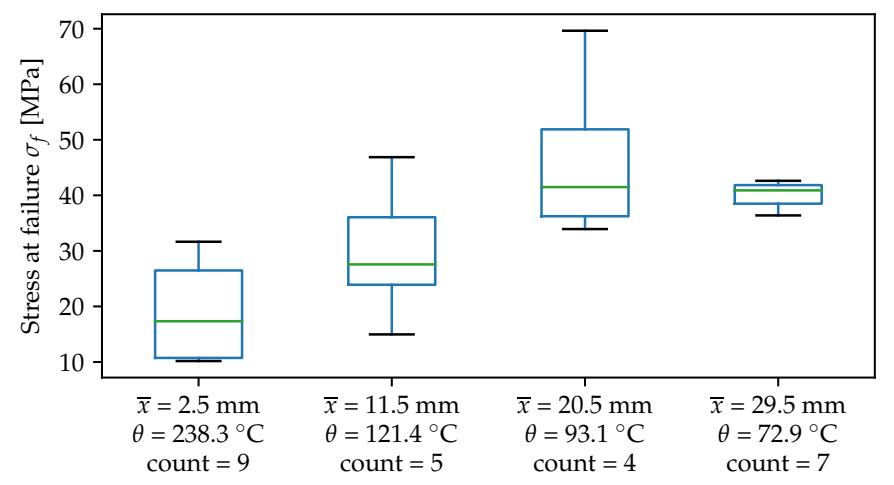

(d)

Figure 17. Tensile strength: (a) S14 (20.24 min, A), (b) S10 (30.82 min, A), (c) S12 (40.70 min, A), (d) S16 (60.61 min, A). 
That strength is more affected by temperature than stiffness is also seen in Table 3 collecting averages from all tests for individual beams. The number in parenthesis represents the beam from the same fire test subjected to 3 PB.

Table 3. Averages of Young's modulus of elasticity and tensile strength from tensile tests.

\begin{tabular}{ccccc}
\hline $\begin{array}{c}\text { Beam } \\
\text { No. }\end{array}$ & $\begin{array}{c}\boldsymbol{t} \\
{[\mathrm{min}]}\end{array}$ & $\begin{array}{c}E_{t} \text { (Category A) } \\
{[\mathrm{GPa}]}\end{array}$ & $\begin{array}{c}E_{t} \text { (Category B) } \\
{[\mathrm{GPa}]}\end{array}$ & $\begin{array}{c}\sigma_{t} \text { (Category A) } \\
{[\mathbf{M P a}]}\end{array}$ \\
\hline $10(9)$ & 30.82 & 10.56 & 10.14 & 42.78 \\
$12(11)$ & 40.70 & 10.40 & 10.53 & 35.36 \\
$14(13)$ & 20.24 & 13.12 & 12.80 & 51.70 \\
$16(15)$ & 60.61 & 9.88 & 10.08 & 31.96 \\
\hline
\end{tabular}

In general, it is difficult to directly compare the tensile properties derived from a bending test with those obtained from pure tension. This is because the stress state in the beam cross-section in bending is a combination of tensile, compressive and shear stresses. It has also been suggested in [8] and confirmed by the present results, see Tables 2 and 3, that the decrease in strength in pure tension is more significant than in bending. Nevertheless, comparing Young's moduli from both tables allows us to support the choice of the value of zero-strength layer $d_{0}=7 \mathrm{~mm}$ if no better estimate, e.g., based on the temperature profile, is available. Although this seems satisfactory for GLT beams loaded by standard fire, we do not wish to generalize this conclusion to other structures and more complex fire scenarios $[13,27]$.

\section{Discussion}

A satisfactory estimate of residual mechanical properties of wooden constructions exposed to fire plays a key role in increasing safety and minimizing the risk of failure. The present paper is another contribution addressing this issue. The principal conclusions draw on the combination of results from full-scale fire tests performed on GLT beams made of spruce wood (Picea abies), small-scale standard tests on specimens produced directly from the beams sustaining fire, and numerical prediction of temperature at the specimen location.

It has been shown in Figures $16 \mathrm{~b}$ and 17 that the residual tensile strength of spruce wood might be substantially reduced at subcharring temperatures not exceeding $250{ }^{\circ} \mathrm{C}$. This result is usually explained by an increase in crystallinity accompanied by thermal degradation of hemicellulose due to high temperatures which in turn increases brittleness and consequently reduces the tensile strength. These processes resulting in permanent changes in wood microstructure and consequently also in mechanical properties are best visible from the results obtained for the beam S16 exposed to fire for the longest exposure time. On the other hand, the results presented in Figure 16 do not suggest a significant influence of elevated temperature on the residual modulus of elasticity, contrary to immediate properties, thus supporting the thermal recovery of this parameter for the range of the observed subcharring temperatures. Although we observed in some cases an increase in Young's modulus at locations adjacent to the charring front, see Figure 15, it is hardly possible to associate this directly with increasing crystallinity as often proposed in the literature.

The results from tensile tests were examined also in the light of three-point bending tests of eight specimens categorized by their cross-sectional dimensions into Group 1 (width $b=100 \mathrm{~mm}$ ) and Group 2 (width $b=160 \mathrm{~mm}$ ). We observed that the tensile strength and stiffness in bending is substantially reduced for beams in Group 1 experiencing much higher temperatures in the residual cross-section during fire when compared to beams in Group 2, recall Figure 10. On the other hand, the stiffness derived from both bending and tensile tests from beams and specimens in Group 2 consistently centers around $10 \mathrm{GPa}$, see also [25]. It is also seen that the residual bending strength is less affected than the strength in pure tension. However, remember that the results from 3 PB were estimated on the 
grounds of zero-strength layer $d_{0}$ set equal to $7 \mathrm{~mm}$ as recommended by Eurocode [24]. So, relying purely on the results from standard tensile tests would promote a reduction of $d_{0}$ for wider beams in Group 2, while $d_{0}$ for beams in Group 1 would considerably exceed the standard value. Clearly, apart from the type of structure, the value of $d_{0}$ depends on the beam dimensions, duration, and the type of fire scenario. Because the zero-strength layer reflects a negative impact of permanent changes in wood microstructure on strength, it might be proposed to link the value of $d_{0}$ to a specific temperature observed in the residual cross-section during fire, recall Figure 11. Numerical simulations presented in Section 3.2 reflect all the mentioned conditions. For spruce wood, the temperature of $200{ }^{\circ} \mathrm{C}$ seems reasonable. However, this must be yet confirmed by more advanced calculations taking into account rigorously the actual three-dimensional stress-state and material anisotropy within an advanced constitutive model [28].

\section{Conclusions}

A group of glued laminated timber beams with cross-sectional dimensions of $320 \mathrm{~mm} \times 100 \mathrm{~mm}$ and $320 \mathrm{~mm} \times 160 \mathrm{~mm}$ made of spruce wood was exposed to a standard fire lasting from 20 to $60 \mathrm{~min}$. The following principal conclusions can be drawn for the resulting temperature profiles and corresponding thermally reduced mechanical properties:

- Both the measured temperatures and temperature profiles reconstructed by FEM simulations indicate a moderate temperature at the central part of the beam crosssection not exceeding $100{ }^{\circ} \mathrm{C}$ throughout the test. The only exception was the $320 \mathrm{~mm} \times 100 \mathrm{~mm}$ beam exposed to $60 \mathrm{~min}$ fire where both the measured and simulated temperature slightly rose above this value.

- The residual values of the tensile strength are significantly affected by elevated temperature $\left(200-240{ }^{\circ} \mathrm{C}\right)$ observed in the narrow zone $(0-5 \mathrm{~mm})$ adjacent to the charring front. Therein, the tensile strength was found about one half of its original value.

- In agreement with general findings, the impact of elevated temperatures on the residual values of Young's moduli is noticeably less pronounced. This is explained by opposing phenomena taking place simultaneously, namely transformation of crystalline cellulose and hemicellulose, reduction of moisture content, and thermal recovery.

- From this perspective, the simplified approach suggested in Eurocode, i.e., reducing the cross-section by $d_{\text {eff }}=2\left(d_{\text {char }}+d_{0}\right)$, is a valid approximation to estimate the beam reduced bearing capacity for typical fires scenarios. Nevertheless, a caution is at place when considering a long fire duration for which the temperature profile might reach significant values even in the central part of the beam cross-section.

Author Contributions: Conceptualization: L.K., M.Š., T.J. and G.M., methodology: L.K., M.Š. and T.J., fire and bending tests: L.K., M.Š. and T.J., tensile tests: P.P. and L.K., transport analysis: J.S., writing-original draft M.Š., writing—review and editing: M.Š., T.J., J.S. and G.M., supervision: G.M., project administration, T.J. All authors have read and agreed to the published version of the manuscript.

Funding: We are thankful for financial support provided by the Czech Grant Agency, project No. 1805791S.

Data Availability Statement: Not applicable.

Conflicts of Interest: The authors declare no conflict of interest.

\section{References}

1. Yildiz, S.; Gezer, E.D.; Yildiz, U.C. Mechanical and chemical behavior of spruce wood modified by heat. Build. Environ. 2006, 41, 1762-1766. [CrossRef]

2. Goodrich, T.; Nawaz, N.; Feih, S.; Lattimer, B.; Mouritz, A. High-temperature mechanical properties and thermal recovery of balsa wood. J. Wood Sci. 2010, 56, 437-443. [CrossRef]

3. Šejnoha, M.; Janda, T.; Melzerová, L.; Nežerka, V.; Šejnoha, J. Modeling glulams in linear range with parameters updated using Bayesian inference. Eng. Struct. 2017, 138, 293-307. [CrossRef] 
4. Šejnoha, M.; Janda, T.; Vorel, J.; Kucíková, L.; Padevět, P.; Hrbek, V. Bayesian inference as a tool for improving estimates of effective elastic parameters of wood. Comput. Struct. 2019, 218, 94-107. [CrossRef]

5. Šejnoha, M.; Sýkora, J.; Vorel, J.; Kucíková, L.; Antoš, J.; Pokorný, J.; Pavlík, Z. Moisture induced strains in spruce from homogenization and transient moisture transport analysis. Comput. Struct. 2019, 220, 114-130. [CrossRef]

6. Östman, B.L. Wood tensile strength at temperatures and moisture contents simulating fire conditions. Wood Sci. Technol. 1985, 19, 103-116. [CrossRef]

7. Zhong, Y.; Zhou, H.; Wen, L. The Effect of Elevated Temperature on Bending Properties of Normal Wood inside Chinese Larch Wood during Fire Events. BioResources 2015, 10, 2926-2935. [CrossRef]

8. Boonstra, M.; Acker, J.; Tjeerdsma, B.; Kegel, E. Strength properties of thermally modified softwoods and its relation to polymeric structural wood constituents. Ann. For. Sci. 2007, 64, 679-690. [CrossRef]

9. Esteves, B.; Pereira, H. Wood modification by heat treatment: A review. BioResources 2009, 4, 370-404. [CrossRef]

10. Law, P.; Barrett, J. Modelling Tension Strength Behaviour of Structural Lumber Exposed to Elevated Temperatures. Fire Saf. Sci. 1997, 5, 1177-1188. [CrossRef]

11. Lange, D.; Boström, L.; Schmid, J.; Albrektsson, J. The Influence of Parametric Fire Scenarios on Structural Timber Performance and Reliability; Technical Report; Project No. 303-121; SP Technical Research Institute of Sweden: Borås, Sweden, 2014.

12. Klippel, M.; Frangi, A.; Hugi, E. Experimental Analysis of the Fire Behavior of Finger-Jointed Timber Members. ASCE J. Struct. Eng. 2013, 140, 04013063. [CrossRef]

13. Schmid, J.; Just, A.; Klippel, M.; Fragiacomo, M. The Reduced Cross-Section Method for Evaluation of the Fire Resistance of Timber Members: Discussion and Determination of the Zero-Strength Layer. Fire Technol. 2015, 51, 1285-1309. [CrossRef]

14. Kubojima, Y.; Okano, T.; Ohta, M. Bending strength and toughness of heat-treated wood. J. Wood Sci. 2000, 46, 8-15. [CrossRef]

15. Bekhta, P.; Niemz, P. Effect of High Temperature on the Change in Color, Dimensional Stability and Mechanical Properties of Spruce Wood. Holzforschung 2003, 57, 539-546. [CrossRef]

16. Kucíková, L.; Janda, T.; Šejnoha, M.; Sỳkora, J. Experimental investigation of fire resistance of GLT beams. Int. J. Comput. Methods Exp. Meas. 2020, 8, 99-110.

17. White, R.; Schaffer, E. Transient moisture gradient in fire exposed wood slab. Wood Fiber Sci. 1981, 12, 17-38.

18. Frandsen, H.L.; Damkilde, L.; Svensson, S. A revised multi-Fickian moisture transport model to describe non-Fickian effects in wood. Holzforschung 2007, 61, 563-572. [CrossRef]

19. Eitelberger, J.; Hofstetter, K.; Dvinskikh, S.V. A multi-scale approach for simulation of transient moisture transport processes in wood below the fiber saturation point. Compos. Sci. Technol. 2011, 71, 1727-1738. [CrossRef]

20. Janssens, M.L. Modeling of the thermal degradation of structural wood members exposed to fire. Fire Mater. 2004, 28, 199-207. [CrossRef]

21. Yuen, R.; Yeoh, G.; de Vahl Davis, G.; Leonardi, E. Modelling the pyrolysis of wet wood-I. Three-dimensional formulation and analysis. Int. J. Heat Mass Transf. 2007, 50, 4371-4386. [CrossRef]

22. König, J.; Walleij, L. One-Dimensional Charring of Timber Exposed to Standard and Parametric Fires in Initially Protected and NonProtected Fire Situation; Technical Report; Report No. I 9908029; Trätake: Swedisch Institute for Wood Technology Research: Stockholm, Sweden, 1999.

23. Melzerová, L.; Šejnoha, M. Interpretation of Results of Penetration Tests Performed on Timber Structures in Bending. Appl. Mech. Mater. 2014, 486, 347-352. [CrossRef]

24. Eurocode 5: Design of Timber Structures-Part 1-2: General-Structural Fire Design; European Committee for Standardization: Brussels, Belgium, 2004; Incorporating corrigendum April 2009.

25. Kucíková, L.; Šejnoha, M.; Janda, T.; Padevět, P.; Marseglia, G. Evaluation of impact of elevated temperatures on Young's modulus of GLT beams. Acta Polytech. CTU Proc. 2021, 30, 41-47. [CrossRef]

26. Schaffer, E. Structural Fire Design: Wood; Technical report; U.S. Department of Agriculture: Madison, WI, USA, 1984.

27. Schmid, J.; König, J.; Just, A. The Reduced Cross-Section Method for the Design of Timber Structures Exposed to Fire-Background, Limitations and New Developments. Struct. Eng. Int. 2012, 22, 514-522. [CrossRef]

28. Šmídová, E.; Kabele, P. Constitutive model for timber fracture under tensile and shear loads. Appl. Mech. Mater. 2015, 784, 137-144. [CrossRef] 